\title{
Bioconcentration factor of perfluorochemicals for each aerial part of rice
}

\author{
Geun-Hyoung Choi ${ }^{1} \cdot$ Deuk-Yeong Lee ${ }^{2} \cdot J_{i}$ Yeon Bae ${ }^{2} \cdot$ Jin-Ho Rho ${ }^{1} \cdot$ \\ Byung-Cheol Moon ${ }^{1} \cdot$ Jin-Hyo Kim² (D)
}

\section{수도작 작물의 과불소화합물 흡수이행성}

최근형 ${ }^{1}$ - 이득영 ${ }^{2} \cdot$ 배지연 $^{2} \cdot$ 노진호 $^{1}$ - 문병철 ${ }^{1} \cdot$ 김진효 $^{2}$

Received: 30 April 2018 / Accepted: 31 May 2018 / Published Online: 30 June 2018

(C) The Korean Society for Applied Biological Chemistry 2018

\begin{abstract}
Perfluorooctanoic acid (PFOA) and perfluorooctane sulfonic acid (PFOS) are emerging pollutants in agricultural product, and the residual patterns and the uptake potentials were only studied on several crops, not on rice. The residue level and bioconcentration factor (BCF) of PFOA and PFOS were investigated on the low $\left(1 \mathrm{mg} \mathrm{kg}^{-1}\right)$ and the high contaminated soil $\left(5 \mathrm{mg} \mathrm{kg}^{-1}\right)$ groups. The residue levels in brown rice in the low group and in the high group were 0.002-0.004 and 0.008-0.030 $\mathrm{mg} \mathrm{kg}^{-1}$ of the each perfluorinated compounds (PFCs), and in the rice husk were $0.035-0.074 \mathrm{mg} \mathrm{kg}^{-1}$ and $0.125-0.376 \mathrm{mg} \mathrm{kg}^{-1}$ of the each PFCs, respectively. Furthermore, the residues in rice straw were the highest level in the all rice parts both in the groups. The PFOA and PFOS were reached to $3.723 \mathrm{mg} \mathrm{kg}^{-1}$ and 7.641 $\mathrm{mg} \mathrm{kg}^{-1}$, respectively, and the BCF (1.474 and 4.700) as well.
\end{abstract}

Keywords Bioconcentration factor - Perfluorooctane sulfonic acid $\cdot$ Perfluorooctanoic acid $\cdot$ Plant uptake $\cdot$ Rice

Geun-Hyoung Cho and Deuk-Yeong Lee are equally contributed.

Jin-Hyo $\operatorname{Kim}(\bowtie)$

E-mail: jhkim75@gnu.ac.kr

${ }^{1}$ Chemical Safety Division, National Institute of Agricultural Sciences, RDA, Wanju 55365, Republic of Korea

${ }^{2}$ Department of Agricultural Chemistry, Institute of Agriculture and Life Science (IALS), Gyeongsang National University, Jinju 52828, Republic of Korea

This is an Open Access article distributed under the terms of the Creative Commons Attribution Non-Commercial License (http://creativecommons. org/licenses/by-nc/3.0/) which permits unrestricted non-commercial use, distribution, and reproduction in any medium, provided the original work is properly cited.

\section{서 론}

과불소화합물(perfluorinated compounds, PFCs)은 1950년대부터 생산되어 금속, 제지, 섬유, 전자산업 등에 광범위한 용도로 사 용되고 있는 물질이다 $[1,2]$. 이로 인해, 과불소화합물의 환경매 체 중 잔류 농도는 $\mathrm{ng} \mathrm{kg}^{-1}$ 수준 이상으로 꾸준히 보고되고 있 고, 이들 중 긴 탄소사슬을 갖는 물질은 난분해성과 생물농축 성, 열안정성 및 높은 수용성으로 인해 인체 및 환경 위해성이 끊임없이 제기되고 있다[2,3,4]. 특히, perfluorooctanoic acid (PFOA)와 perfluorooctane sulfonic acid (PFOS)는 수계와 토양 에서 가장 빈번히 검출되는 $\mathrm{PFCs}$ 물질로 알려져 있으며, 이들 중 PFOS 및 유도체들은 Stockholm Convention에서 잔류성유 기오염물질(persistent organic pollutants, POPs)로 지정되어 있 다[3,5]. 따라서, 이들 PFCs의 환경 잔류로 인한 생태계 먹이사 슬 내 오염과 오염 식품섭취로 인한 인체 위해성 발생가능성은 꾸준히 문제제기되고 있다.

유럽식품안전위원회(European Food Safety Authority)에서는 2008년 PFOA와 PFOS의 일일섭취허용량(tolerable daily intakes, $\mathrm{TDI})$ 을 $1500 \mathrm{ng} / \mathrm{kg} / \mathrm{day}$ 와 $150 \mathrm{ng} / \mathrm{kg} / \mathrm{day}$ 로 각각 설정하였고, $\mathrm{C}_{6}$ 이상의 긴 탄소 사슬을 갖는 $\mathrm{PFCs}$ 에 대해서는 대체 소재 사용 을 권고하고 있으나 환경에서의 난분해성과 생물농축성으로 인 해 우유와 물 등 다양한 식품에서 여전히 검출 빈도가 높은 것 으로 보고되고 있다[2,6,7,8].

$\mathrm{PFCs}$ 의 인체노출기여도는 식품을 통한 섭취가 가장 높은 것 으로 보고되고 있으며, 이들 중 농산물은 오염된 토양과 물로 부터 직접적인 흡수 이행을 통한 오염 가능성이 높아 경작지 잔 류 오염 관리가 무엇보다 중요하다[9,10]. Choi 등[11]은 국내 농 경지 토양과 관개수 중 $\mathrm{PFCs}$ 잔류 수준을 보고한 바 있고, 이 를 일부 국가의 토양 및 수계 PFCs 모니터링 조사결과와 비교 해 보면, $\mu \mathrm{g} \mathrm{kg}^{-1}$ 이하의 낮은 잔류 수준을 나타내고 있음을 확 인할 수 있다[12]. 또한, 국내 유통 식품군에서의 PFCs 잔류 모 
니터링 결과도 $\mathrm{ng} \mathrm{kg}^{-1}$ 수준에서 보고되고 있다. 하지만, 이러 한 식품 모니터링은 매우 제한적으로 수행되어 국내 생산 농산 물의 PFCs 안전성을 명확히 담보하지 못하는 실정이다 $[6,7,9,13]$. 특히, PFCs 잔류 경작지로부터 안전농산물을 생산하 기 위해서는 작물 별 흡수이행성을 산출하고 이를 근거로 한 경작지 안전관리 정책이 마련되어야 하지만, $\mathrm{PFOA}$ 와 $\mathrm{PFOS}$ 의 작물흡수이행 수준에 관한 구체적이고 다양한 연구결과가 여전 히 부족하다. 최근까지 보고된 $\mathrm{PFOA}$ 와 $\mathrm{PFOS}$ 의 작물흡수이행 성에 대한 연구 결과는 감자, 밀, 오이, 토마토 등 일부 작물에 제한되어 있으며 $[10,14,15,16]$, 국내 주요 식량 작물인 쌀에 대 한 PFCs 생물농축성에 관한 연구와 보고는 지금까지 없었다.

국내 주요 식량 작물인 벼에서 생산되는 쌀은 일일섭취량이 $183 \mathrm{~g}$ 으로 식이섭취 노출량 산정에서 빼놓을 수 없는 곡물이며 [17], 서양 국가와 달리 쌀을 주요 영양원으로 하는 한국에서 쌀을 중심으로 한 POPs 모니터링과 농업환경 관리기준 설정연 구는 절대 빼놓을 수 없다. 따라서, 본 연구에서는 주요 식량 작물인 벼에 대한 $\mathrm{PFOA}$ 와 $\mathrm{PFOS}$ 의 작물흡수이행성을 현미와 왕겨, 볏짚으로 구분하여 평가하였다.

\section{재료 및 방법}

\section{표준품 및 시약}

시험에 사용한 PFOA와 PFOS 표준품( $>98 \%)$ 은 Wellington Laboratories (Guelph, ON, Canada)에서, methanol, acetonitrile, acetic acid, ammonium acetate, tetrahydrofuran은 HPLC급으로 Merck (Darmstadt, Germany)에서 구입하여 사용하였으며, ENVI-Carb ${ }^{\mathrm{TM}}$ 은 Supleco Co. (Bellefonte, PA, USA)에서, HLB 카트리지 $(0.5 \mathrm{~g}, 6 \mathrm{~mL})$ 는 Waters (Milford, DE, USA)에서 구입하여 사용하였다.

\section{토양 준비 및 벼 재배}

시험토는 Choi 등[18]이 사용한 것과 동일한 토양을 사용하였 다. 시험토에 $30 \%(\mathrm{v} / \mathrm{v})$ methanol에 녹여진 $\mathrm{PFOA}$ 와 $\mathrm{PFOS}$ 를 이용하여 명목상 토양의 농도가 각각 $1 \mathrm{mg} \mathrm{kg}^{-1}$ 과 $5 \mathrm{mg} \mathrm{kg}^{-1}$ 이 되도록 처리한 후 $48 \mathrm{~h}$ 동안 균질화하고 $1 / 2000 \mathrm{a}$ 포트에 담아 30 일간 숙성하였다. 반복시험구는 각 오염 농도별로 16 개의 포 트를 두었고, 숙성된 토양은 오염초기농도를 확인하고자 벼 이 앙 전 토양 잔류 분석용 시료로 채취하였다. 벼는 신동진 품종 을 6월 상순에 온실에서 이앙하였고, 이앙 후 138 일 경과 시점 에 수확하였으며, 벼 생육조건과 재배조건은 Choi 등[18]과 동 일하였다. 수확된 벼는 탈곡 후 후드에서 음건하고, 실험용 도 정기(TR200, Kett Electric Laboratory, Tokyo, Japan)를 사용하 여 현미와 왕겨로 구분한 뒤 시료를 드라이아이스와 함께 분쇄 하고 분석 전까지 $-20^{\circ} \mathrm{C}$ 에서 냉동 보관하였다.

\section{토양 및 작물 중 PFCs 분석}

Choi 등[11]의 방법에 따라 토양 중 $\mathrm{PFCs}$ 를 정량분석 하였다. 토양 $1.0 \mathrm{~g}$ 을 $1 \%$ acetic acid $(10 \mathrm{~mL})$ 로 추출한 뒤 $3000 \mathrm{rpm}$ 에서 원심분리(Hanil Science Co., Seoul, Korea)하여 상등액을 취하고, methanol $/ 1 \%$ acetic acid $(90 / 10, v / v)$ 를 이용하여 재추 출 $(10 \mathrm{~mL} \times 2)$ 한 뒤, 추출액을 $15 \mathrm{~mL}$ 까지 질소농축하고, 증류수
$185 \mathrm{~mL}$ 를 넣어 희석하였다. 희석액은 HLB 카트리지를 사용하 여 고정상 추출하였다. 작물체 중 $\mathrm{PFCs}$ 분석은 BallesterosGomez 등[19]의 방법에 따라 시료 $1.0 \mathrm{~g}$ 을 methanol/water (75/ $25, v / v)(10 \mathrm{~mL})$ 로 추출한 뒤 원심분리하여 상등액을 분취하고, tetrahydrofuran/water $(75 / 25, v / v)$ 를 이용하여 재추출 $(10 \mathrm{~mL} \times 2)$ 한 뒤, 추출액을 $15 \mathrm{~mL}$ 까지 질소농축하고, 증류수 $185 \mathrm{~mL}$ 를 넣 어 희석하였다. 희석액은 HLB 카트리지를 사용하여 고정상 추 출하였다. 토양 및 작물에서의 정제 추출물은 질소 농축 후 1.0 $\mathrm{mL}$ methanol로 재용해 한 뒤, ENVI-Carb ${ }^{\mathrm{TM}} 20 \mathrm{mg}$ 을 넣고 vortex 및 원심분리 후 상등액을 nylon filter로 걸러내었다. 시 료의 예상 잔류농도가 정량범위를 초과할 경우 methanol을 사 용하여 적정범위까지 희석한 뒤 분석에 사용하였다. 시료 정제 용액은 ${ }^{13} \mathrm{C}$-동위원소가 포함된 $\mathrm{PFOA}$ 와 $\mathrm{PFOS}$ 를 internal standard로 넣어주고, LC-MS/MS를 통하여 정량분석하였다. 기 기분석 장비 및 조건은 Choi 등[11]의 방법과 동일하였다.

\section{PFCs 분석법 검중}

본 실험의 $\mathrm{PFOA}$ 와 $\mathrm{PFOS}$ 정량분석에는 ${ }^{13} \mathrm{C}_{8}$-동위원소가 포함 된 Injection standard를 사용하여 $0.005-1.000 \mu \mathrm{g} \mathrm{kg}^{-1}$ 범위에서 linearity를 측정하였고, $\mathrm{PFOA}$ 와 $\mathrm{PFOS}$ 모두 $\mathrm{R}^{2}$ 가 0.999 이상이 었다. 토양과 작물시료에 대한 정량한계는 $\mathrm{PFOA}$ 와 $\mathrm{PFOS}$ 가 각 각 0.020 과 $0.005 \mu \mathrm{g} \mathrm{kg}^{-1}$ 이었다. 토양, 현미, 왕겨, 볏짚에서 회 수율은 ${ }^{13} \mathrm{C}_{4}$-동위원소가 포함된 $\mathrm{PFOA}$ 와 $\mathrm{PFOS}$ 를 사용하여 $0.100 \mu \mathrm{g} \mathrm{kg}^{-1}$ 와 $0.500 \mu \mathrm{g} \mathrm{kg}^{-1}$ 두 처리 수준에서 시험하였고, $70.8-82.2 \%$ 로 확인되었다. 분석에 대한 상대표준편차는 모든 시 료에서 8.4-9.8\%로 확인되었다.

\section{PFCs 생물농축계수 산출}

생물농축계수(bioconcentration factor, $\mathrm{BCF}$ )는 Choi 등[18]이 사 용한 방법으로 산출하였다.

\section{결과 및 고찰}

\section{PFCs의 벼 잔류량}

본 시험은 명목상 $\mathrm{PFOA}$ 및 $\mathrm{PFOS}$ 의 농도를 저농도 오염시험 구 $\left(1 \mathrm{mg} \mathrm{kg}^{-1}\right)$ 와 5 배 수준인 고농도 오염시험구 $\left(5 \mathrm{mg} \mathrm{kg}^{-1}\right)$ 에서 작물흡수이행 시험을 진행하였다. 벼 이앙 시점 토양 중 $\mathrm{PFOA}$ 와 $\mathrm{PFOS}$ 는 저농도 오염시험구에서 각각 $0.968 \mathrm{mg} \mathrm{kg}^{-1}$ 과 0.789 $\mathrm{mg} \mathrm{kg}^{-1}$ 였으며, 고농도 오염시험구는 각각 $4.844 \mathrm{mg} \mathrm{kg}^{-1}$ 과 $4.370 \mathrm{mg} \mathrm{kg}^{-1}$ 이었다(Table 1).

벼의 $\mathrm{PFCs}$ 의 잔류량은 현미와 왕겨, 볏짚으로 구분하여 잔류 량을 조사하였다. 특히 식용인 현미와 사료용인 볏짚의 잔류는 직접 혹은 먹이사슬을 통해 인간에게 전달될 수 있어 작물잔류 이행율 조사는 매우 중요한 의미를 갖는다. 저농도 오염처리구 에서 $\mathrm{PFOA}$ 와 $\mathrm{PFOS}$ 의 현미 중 잔류 농도는 각각 $0.004 \mathrm{mg}$ $\mathrm{kg}^{-1}$ 과 $0.002 \mathrm{mg} \mathrm{kg}^{-1}$ 으로 확인되었으나, 고농도 오염처리구의 현 미 시료에서는 각각 $0.030 \mathrm{mg} \mathrm{kg}^{-1}$ 과 $0.008 \mathrm{mg} \mathrm{kg}^{-1}$ 이 확인되었 다. 특히, 현미에서는 PFOS의 잔류가 PFOA에 비해 다소 낮음 을 확인할 수 있었다. 왕겨 중 $\mathrm{PFOA}$ 와 $\mathrm{PFOS}$ 의 잔류 농도는 저농도 오염처리구에서 각각 $0.035 \mathrm{mg} \mathrm{kg}^{-1}$ 와 $0.074 \mathrm{mg} \mathrm{kg}^{-1}$ 로 확인되었으며, 고농도 오염 처리구에서는 $0.125 \mathrm{mg} \mathrm{kg}^{-1}$ 와 0.376 
Table 1 PFCs residue in soil and the each part of rice and their BCF values

\begin{tabular}{|c|c|c|c|c|c|c|c|c|}
\hline & \multicolumn{2}{|c|}{ Soil } & \multicolumn{2}{|c|}{ Steam } & \multicolumn{2}{|c|}{ Rice husk } & \multicolumn{2}{|c|}{ Brown rice } \\
\hline & PFOA & PFOS & PFOA & PFOS & PFOA & PFOS & PFOA & PFOS \\
\hline Low group & 0.968 & 0.789 & 1.427 & 3.708 & 0.035 & 0.074 & 0.004 & 0.002 \\
\hline BCF & & & 1.474 & 4.700 & 0.036 & 0.094 & 0.004 & 0.003 \\
\hline High group & 4.844 & 4.370 & 3.723 & 7.641 & 0.125 & 0.376 & 0.030 & 0.008 \\
\hline $\mathrm{BCF}$ & & & 0.769 & 1.749 & 0.026 & 0.086 & 0.006 & 0.002 \\
\hline
\end{tabular}

$\mathrm{mg} \mathrm{kg}$ 으로 확인되었다. 이와 함께, 볏짚에서의 PFCs 잔류량 은 저농도와 고농도 오염 처리구에서 $\mathrm{PFOA}$ 가 각각 1.427 , $3.723 \mathrm{mg} \mathrm{kg}^{-1}$ 이었고, PFOS 잔류량은 각각 $3.708,7.641 \mathrm{mg}$ $\mathrm{kg}^{-1}$ 로 확인되었다. 왕겨와 볏짚은 현미와 달리 PFOS의 잔류량 이 PFOA에 비해 다소 높은 경향이 나타났다. 특히, 사료용으 로 주로 사용되는 볏짚에서의 높은 PFCs 잔류양상은 PFCs 위 해 평가와 관리를 위해 집중적으로 검토되어야 할 것으로 생각 된다.

\section{PFCs의 벼 생물농축계수}

고농도와 저농도에서 수행된 $\mathrm{PFCs}$ 의 벼 흡수이행성 시험은 오 염 초기농도를 기준으로 $\mathrm{BCF}$ 를 산출하여 비교하였다. 현미 중 $\mathrm{PFOA}$ 와 $\mathrm{PFOS}$ 의 $\mathrm{BCF}$ 는 각각 0.004-0.006과 0.002-0.003으로 확인되었고, 왕겨는 0.026-0.036과 0.086-0.094, 볏짚은 0.7691.474 와 1.749-4.700으로 각각 산출되었다. 또한, 볏짚과 왕겨에 서 PFOS의 생물농축계수가 PFOA보다 2-3배 가량 높은 것은 현미에서의 잔류 양상과 다소 차이가 있었다. 특히, 볏짚에서의 $\mathrm{PFCs}$ 생물농축계수는 토마토, 콩, 셀러리의 줄기에서 관찰된 생 물농축계수와 유사하였고, 줄기 부위의 생물농축계수가 열매보 다 높다고 보고된 선행 결과와 유사한 것으로 확인되었다[14].

\section{결 론}

벼는 다른 작물과 달리 열매와 줄기 모두 식용 혹은 사료용으 로 사용되어 중요한 경제적 가치를 가지고 있다. 특히, 난분해 성이며 높은 생물농축성을 갖는 $\mathrm{PFOA}$ 와 $\mathrm{PFOS}$ 의 현미 중 잔 류는 직접적인 식이섭취 노출로 이어질 수 있고, 볏짚에서의 잔 류는 소 급여를 통한 우유 및 육류 잔류로 이어져 간접적 식이 섭취 노출경로가 된다[10]. 따라서, 본 연구결과에서 보여준것과 같이 낮은 잔류 오염 수준과 $\mathrm{BCF}$ 값을 나타낸 현미와 달리 $\mathrm{BCF}$ 가 큰 볏짚의 $\mathrm{PFCs}$ 오염은 우유 및 육류를 통한 $\mathrm{TDI}$ 기 여도를 높일 수 있어, 반드시 사료에 대한 위해평가 및 잔류허 용기준 설정을 검토해야 할 것이다. 특히 이를 위해서는 토양 잔류 $\mathrm{PFCs}$ 에 대한 잔류허용기준 설정 연구가 추가적으로 수행 되어야 할 것이다.

\section{초 록}

국내 주요 식량작물인 벼에서의 잔류성 유기오염물질 잔류평가 는 인체 위해성 평가에서 매우 중요하다. 본 연구에서는 과불 소화합물 중 perfluorooctanoic acid (PFOA)와 perfluorooctane sulfonic acid (PFOS)의 잔류평가를 벼의 부위별 흡수이행성을 조사하여 수행하였다. 벼는 저농도 오염처리구 $\left(1 \mathrm{mg} \mathrm{kg}^{-1}\right)$ 와 고 농도 오염처리구 $\left(5 \mathrm{mg} \mathrm{kg}^{-1}\right)$ 에서 재배 후 현미, 왕겨, 볏짚으로 나누어 잔류량을 조사하였고, 시험결과 현미의 과불소화합물 흡 수이행성 $(0.002-0.006)$ 이 다른 부위에 비해 가장 낮은 것으로 확 인되었다. 잔류수준은 볏짚에서 가장 높게 나타났으며, 다음으 로 왕겨와 현미 순이었고, 볏짚의 $\mathrm{PFOA}$ 와 $\mathrm{PFOS}$ 의 생물농축계 수는 최대 1.474 와 4.700 으로 확인되었다.

Keywords 과불소화합물 - 벼 · 생물농축계수 · 잔류·토양

Acknowledgment This study was supported by the "Cooperative Research Program for Agricultural Science \& Technology Development (Project No. PJ01332102)", National Academy of Agricultural Science, Rural Development Administration, Republic of Korea.

\section{References}

1. Wang Z, Cousins IT, Scheringer M, Buck RC, Hungerbuhler K (2014) Global emission inventories for C4-C14 perfluoroalkyl carboxylic acid (PFCA) homologues from 1951 to 2030, Part I: production and emissions from quantifiable sources. Environ Int 70: 62-75 doi:10.1016/ j.envint.2014.04.013

2. Zareitalabad P, Siemens J, Hamer M, Amelung W (2013) Perfluorooctanoic acid (PFOA) and perfluorooctanesulfonic acid (PFOS) in surface waters, sediments, soils and wastewater-A review on concentrations and distribution coefficients. Chemosphere 91: 725-732 doi:10.1016/j.chemosphere.2013.02.024

3. Arvaniti OS, Stasinakis AS (2015) Review on the occurrence, fate and removal of perfluorinated compounds during wastewater treatment. Sci Total Environ 524-525: 81-92 doi:10.1016/j.scitotenv.2015.04.023

4. Kim JH, Ok YS, Choi GH, Park BJ (2015) Residual perfluorochemicals in the biochar from sewage sludge. Chemosphere 134: 435-437 doi:10.1016/j.chemosphere.2015.05.012

5. Choi GH, Lee DY, Seo DC, Kim LS, Lim SJ, Ryu SH, Park BJ, Kim JH, Kim JH (2018a) Endosulfan Plant Uptake Suppression Effect on Char Amendment in Oriental Radish. Water Air Soil Pollut. 229: 24. doi.org/ 10.1007/s11270-017-3677-x

6. Heo JJ, Lee JW, Kim SK, Oh JE (2014) Foodstuff analyses show that seafood and water are major perfluoroalkyl acids (PFAAs) sources to humans in Korea. J Hazard Mater 279: 402-409 doi:10.1016/ j.jhazmat.2014.07.004

7. Pérez F, Llorca M, Köck-Schulmeyer M, Škrbić B, Oliveira LS, da Boit Martinello K, Al-Dhabi NA, Antić I, Farré M, Barceló D (2014) Assessment of perfluoroalkyl substances in food items at global scale. Environ Res 135: 181-189 doi:10.1016/j.envres.2014.08.004

8. Post GB, Cohn PD, Cooper KR (2012) Perfluorooctanoic acid (PFOA), an emerging drinking water contaminant: a critical review of recent literature. Environ Res 116: 93-117 doi:10.1016/j.envres.2012.03.007 
9. Clarke DB, Bailey VA, Routledge A, Lloyd AS, Hird S, Mortimer DN, Gem M (2010) Dietary intake estimate for perfluorooctanesulphonic acid (PFOS) and other perfluorocompounds (PFCs) in UK retail foods following determination using standard addition LC-MS/MS. Food Addit Contam Part A Chem Anal Control Expo Risk Assess 27: 530545 doi:10.1080/19440040903476590

10. van Asselt ED, Kowalczyk J, van Eijkeren JCH, Zeilmaker MJ, Ehlers S, Furst P, Lahrssen-Wiederholt M, van der Fels-Klerx HJ (2013) Transfer of perfluorooctane sulfonic acid (PFOS) from contaminated feed to dairy milk. Food Chem 141: 1489-1495 doi:10.1016/ j.foodchem.2013.04.035

11. Choi GH, Lee DY, Jeong DK, Kuppusamy S, Lee YB, Park BJ, Kim JH (2017) Perfluorooctanoic acid (PFOA) and perfluorooctanesulfonic acid (PFOS) concentrations in the South Korean agricultural environment: A national survey. J. Integr. Agric. 16: 1841-1851

12. Lam NH, Cho CR, Lee JS, Soh HY, Lee BC, Lee JA, Tatarozako N, Sasaki K, Iwabuchi K, Kannan K, Cho HS (2014) Perfluorinated alkyl substances in water, sediment, plankton and fish from Korean rivers and lakes: a nationwide survey. Sci Total Environ 491-492:154-162 doi:10.1016/j.scitotenv.2014.01.045

13. Kim HY, Kim SK, Kang DM, Hwang YS, Oh JE (2014) The relationships between sixteen perfluorinated compound concentrations in blood serum and food, and other parameters, in the general population of South Korea with proportionate stratified sampling method. Sci Total Environ 470-471: 1390-1400 doi:10.1016/j.scitotenv.2013.06.039

14. Blaine AC, Rich CD, Sedlacko EM, Hundal LS, Kumar K, Milis MA,
Harris KM, Higgins CP (2014) Perfluoroalkyl acid distribution in various plant compartments of edible crops grown in biosolids-amended soils. Environ Sci Technol 48: 7858-7865 doi:10.1021/es500016s

15. Lechner M, Knapp H (2011) Carryover of perfluorooctanoic acid (PFOA) and perfluorooctane sulfonate (PFOS) from soil to plant and distribution to the different plant compartments studied in cultures of carrots (Daucus carota ssp. Sativus), potatoes (Solanum tuberosum), and cucumbers (Cucumis Sativus). J Agric Food Chem 59: 11011-11018 doi:10.1021/jf201355y

16. Zhao H, Guan Y, Zhang G, Zhang Z, Tan F, Quan X, Chen J (2013) Uptake of perfluorooctane sulfonate (PFOS) by wheat (Triticum aestivum L.) plant. Chemosphere 91: 139-144 doi:10.1016/j. chemosphere.2012.11.036

17. Choi GH, Choi DS, Hong SM, Kwon OK, Eun HS, Kim JH, Kim JH (2012) Investigation on Polychlorinated Dibenzo-p-dioxins, Polychlorinated Dibenzofurans and Dioxin-like Polychlorinated Biphenyls of Grains and Estimation of Dietary Intake for Korean. J Appl Biol Chem. 55: 253-261

18. Choi GH, Lee DY, Ryu SH, Park BJ, Moon BC, Kim JH (2018b) Investigation of the Bioconcentration Factor of Endosulfan for Rice from Soil. Korean J Pestic Sci 22: 25-28

19. Ballesteros-Gomez A, Rubio S, van Leeuwen S (2010) Tetrahydrofuranwater extraction, in-line clean-up and selective liquid chromatography/ tandem mass spectrometry for the quantitation of perfluorinated compounds in food at the low picogram per gram level. J Chromatogr A 1217: 5913-5921 doi:10.1016/j.chroma.2010.07.032 